\title{
AC 2007-2327: SAME INTERVENTION, DIFFERENT EFFECT: A COMPARISON OF THE IMPACT OF PORTFOLIO CREATION ON STUDENTS' PROFESSIONAL DEVELOPMENT
}

Zhiwei Guan, University of Washington

Jennifer Turns, University of Washington 


\section{Same Intervention, Different Effect: A Comparison of the Impact of Portfolio Creation on Students' Professional Development}

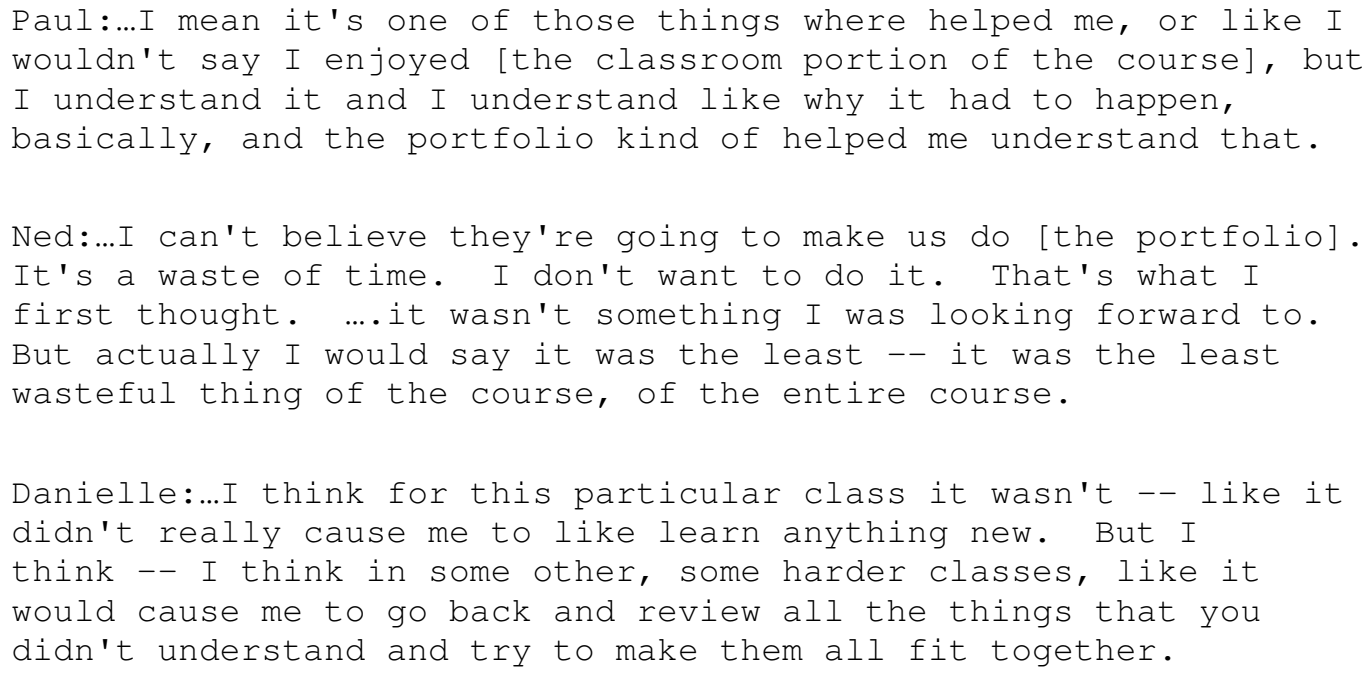

\section{Introduction}

Engineering students need to not only gain the knowledge and skills necessary for engineering practice, but also an understanding of how this knowledge and these skills fit together and support engineering work. It is therefore important for the engineering education community to design curricular materials that help students with these goals.

One such curricular intervention is a professional portfolio. A portfolio is a purposeful collection of student work that tells the story of the student's efforts, progress, or achievement in a given area. Portfolio construction aligns well with the properties of an effective learning environment (i.e., it is concurrently learner-centered, knowledgecentered, assessment-centered, community-centered, and context-centered), and thus represents a promising strategy for promoting knowledge integration and professional development. We define a course-specific professional portfolio as a portfolio in which a student makes claims about his/her preparedness for professional practice and supports the claims through artifacts drawn from a single course. We believe that having students create such portfolios represents a promising practice for helping students consolidate their knowledge and reflect on the connection of this knowledge to engineering practice.

In our work, we have been studying the practice of course-specific portfolio construction. To this end, we conducted a study in winter of 2006 in which 35 junior and senior engineering students in a mechanical engineering class (ME 355 Introduction to Manufacturing Processes) were asked to create course-specific professional portfolios. The portfolio had three required components: a statement in the student discussed his/her preparedness, three or more artifacts from the course that supported the claims made in the statement, and annotations for each artifact to explain what the artifact illustrates. Students were instructed that the artifacts for the portfolio might include work created in 
the course (such as homework and design sketches) but also materials that reflect broader aspects of their course experience (such as meeting minutes, team communication, pictures showing them interacting with equipment). The students were instructed that their portfolios should demonstrate their understanding of the course, their engineering discipline, and their sense of how the skills and knowledge gained through the course have contributed to their understanding of their engineering discipline and their preparedness for engineering practice.

We collected data through multiple methods. Post-surveys were conducted to collect students' self-evaluation of the impact of portfolio construction on different aspects of their understanding. The survey invited students to indicate their level of agreement to statements representing possible benefits of the assignment (e.g., the assignment helped me to gain a better understanding of how the course concepts relate to engineering overall). We also collected the students' portfolios and conducted interviews with a subset of the students to gain insights on the survey results. The interviews were conducted by a research associate not associated with the teaching of the class in order to protect student confidentiality and minimize any risk of coercion. In our broad analysis, we have been focusing on how the students frame the experienced or potential learning benefits of the assignment, the nature of the activity that would lead to the benefits and the conditions under which such benefits did and/or could occur.

This paper takes a case study approach and focuses on how three students (Paul, Nancy, and Dan) made sense of the portfolio assignment. These three cases were chosen because they represent three points along a continuum formed by looking at students' responses on the post-survey survey. Of the three students profiled in this paper, one student responded with strong positive agreement to the statements (the average of the agreement scores was high), one student responded neutrally (the average of the agreement scores was in the neither agree nor disagree range), and one student responded with strong disagreement (the average of the agreement scores was very low). Despite this variation in their responses on the survey, however, all three students were able to talk about the experienced and/or potential benefits of the assignment.

In the sections below, we focus on two benefits reported by all three students and then turn to the issues brought up by the students individually. The quotes at the beginning of the paper provide an encapsulated sense of how the three students understood the assignment. In these quotes and in the rest of the paper, Paul is the student who responded to the survey with positive agreement, Ned is the student who was neutral in the survey, and Danielle is the student who responded by disagreeing with most of the statements. In other words, Paul reported through the survey that he found the portfolio to have benefited his learning, Ned was neutral as to whether the portfolio activity had affected his learning, and Danielle had actively disagreed that the assignment had affected her learning in the course. What is intriguing about the data overall is how all three students, despite their differing attitudes to the role of the portfolio assignment for this specific course, could articulate when and how the portfolio assignment could be beneficial. We return to this issue in the discussion. 


\section{Results I: Benefits reported in all three cases}

Two useful aspects of the portfolio activity were highlighted by all three of the students profiled in this paper. In particular, all three students noted that the portfolio construction could enhance confidence in one's knowledge and also the portfolio itself would be valuable for presenting oneself to employers.

Creating a portfolio improves confidence in knowledge. All three participants reported that the portfolio creation did or could help them build confidence in their knowledge. In particular, they noted that the portfolio activity could help them to see what they have learned and feel ownership of the knowledge or skills.

Danielle: [portfolio] is something that you can fall back on

Ned: Portfolio shows your knowledge (theory and knowledge), and make you know that you have that knowledge

Paul: having to put it down in words helped me crystallize in my mind, having an actual almost feeling of what I learned or what I got out of the class

Portfolio could be useful for presenting themselves to others. Furthermore, all three reported feeling that the portfolio itself is a valuable object for both themselves and future employers. It provides students an "organized" and "visual" way to present what they learned and what they are capable of doing.

Danielle: you are actually trying to make something that's valuable for yourself and for your employers in the future

Ned: the portfolio is organized, cleancut manner of showing whatever it is you want to present.... if you write [the portfolio] as you go with your research, you would, like I say again, question yourself, so that would help you.....and you're trying to explain to other people and show them what you're doing and why you're doing it, and why $\mathrm{X}$ relates to Y.

Paul: if [employers] asked about what experience I have in that kind of area, or also, I mean [the portfolio] is useful in that it made me think about kind of what I learned, so if I got asked questions in an interview, I could explain to them what I know how to do or what I've learning in that kind of area.

\section{Results II: Insights unique to each case}

In the previous section, we discussed two benefits reported by all three participants. What was more pronounced in the data was the different ways in which the students made sense of the assignment and, in particular, the benefits of the assignment, the conditions under which the benefits would occur, and the nature of the activity that would 
lead to the benefits. These are discussed below. We start with Danielle because of the potential fruitfulness of exploring the mismatch between her negative responses on the survey and her positive insights in the interview. We then turn to the insights shared by Ned and Paul. In our treatment of these two latter cases, we not only focus on insights they shared but also points of alignment and difference between their perspectives and Danielle's.

\section{$\underline{\text { Danielle }}$}

As a mechanical engineering student, Danielle had a unique characteristic that she was an interdisciplinary student. As a result, her particular circumstance was that she was taking courses from several different departments.

Portfolios show professors students' skill level and knowledge. A major challenge she noted was that gaps exist between class teaching and students' prior knowledge and skills. She suggested this may occur because professors do not seem to know what students have already learned and what students' skills are. She sees the portfolio as a bridge to connect students' knowledge and skills into the classroom, so that what they learned in the class may fit into each individual's learning plan and goals.

"I'm talking about all of the courses that I've taken at the University of Washington, whether it be in the philosophy department or in the electrical engineering department or even in the mechanical engineering department. Um, like professors don't really know that well what the other people are teaching and what the students already know, so if the -- if the professors were seeing, um, these portfolios, then maybe -- maybe instead of teaching like very discrete chunks, like, okay, now we're going to learn thermodynamics and now we're going to learn like fluid mechanics, like it will all go towards like one finished product."

Portfolios provide students a chance to reflect and synthesize. Danielle was also concerned about the reality of college teaching, where students do not have time to reflect on what they have learned. In her view, students in the class are paying most of their attention to the grade as emphasized by current pedagogical models. Further, students lack opportunities to reconcile what they went through in the class, and often fail to connect the new knowledge to prior knowledge (prior courses or knowledge about profession). The potential result is low retention of knowledge covered in the class.

"I personally hate exams, and I think maybe [the portfolio] could be used to like supplement or replace a final or something, that would be ... Well, instead of cramming and then forgetting all the information and then getting a final, most people don't even look at the final when they get it back. Most people don't even get their finals back, you know. So that's like being higher like -- less third of the course mostly wasted because you don't ever use it again. But this way, if you have some sort of final, you could keep it." 
Danielle thought the portfolio could be a solution to the above mentioned problems in that it could remind both students and professors of what has been taught in the class.

"The portfolio, you get to keep it, and the professor would have a realistic understanding of what the students think is important to them. Um, so instead, like if you made -- instead of nonthreatening, if you made the portfolio bigger, a more important part of the class, and you said instead of a final, then I think that would cause all sorts of good things to happen."

Another particular benefit she saw in the portfolio assignment was to "help students to understand the value of this course in terms of connection to other courses." She emphasized that this is the major point of creating a portfolio.

“...like I think if it's implemented in several classes, then it would -- it would definitely help connect all of them together."

Creating a portfolio in the class will make the learning more efficient. Although Danielle did not think the portfolio helped her in this particular class because "it's a simple class," she could see where the portfolio could be useful in some "harder class" in that it could help her review the course topics and integrate these topics with her prior knowledge. She even noted that if she was required to create a portfolio, this might induce her to choose a more efficient learning strategy, such as taking notes differently or presenting the knowledge learned in a flowchart, to help her synthesize the course's topics.

"I think in some other, some harder classes, like it would cause me to go back and review all the things that you didn't understand and try to make them all fit together.

Yeah, if I were in a different course. I don't know, like I would try to synthesize lectures more into it, like if I had known from the beginning, I might take notes differently or something. I don't know. Um, I have to think about that one, but I think -- I mean I think like the entire course content is something that's, you know, valuable to employers, and if you can present it in like some easy, visual way, like maybe create like a block diagram or something or flowchart."

Portfolios could be used useful when preparing career documents. As a student with an interdisciplinary background, she was also struggling with the complexity of presenting herself to future employers. She reported having to prepare different documents about herself for different audiences. She seemed to suggest that a course-based portfolio could provide her a chance to write statements about the profession and knowledge for each course. If done across her courses, she could accumulate a pool of statements from which she could easily select and revise to fit with the audience needs.

"I mean you end up writing all sorts of different resumes for all sorts of different employers, I mean maybe you want to work for a nonprofit or Microsoft or whatever, and like all the -- all the different cover letters I've written, all the 
different resumes that I've written, have all had a completely different slant. So if you have a bunch of, you know, statements then you can just cut and paste them down. And like the work is already done, instead of having to come up with 10 different -- 10 different statements in one day."

\section{$\underline{\mathrm{Ned}}$}

Ned is the student whose survey responses suggested neutrality or ambivalence about whether the assignment had affected his learning in the course. However, by the time he participated in the interview (which occurred three weeks after the survey), he had realized the portfolio had had a strong impact on him.

Creating the portfolio made him less biased against the course. As compared to Danielle who thought the class was simple, Ned's major challenge in the course was that he lacked interest. Ned initially objected to the fact that he would have to do extra work to create a portfolio for the course. Yet, after creating the portfolio, he reported realizing that the course topics are important and that he had become less "biased" against the course.

"I can't believe they're going to make us do it. It's a waste of time. I don't want to do it. That's what I first thought. Um, plus on top of that, I didn't like the class at all, or the professor. Um, I thought that it was -- the class was pretty boring, and to top it off I had to write a portfolio, so it wasn't something I was looking forward to ...

[the portfolio] helped me not to be so biased against the course."

Creating a portfolio helped motivate learning. In Ned's case, his disinterest in the course seemed to have led to low motivation to learn ("do not want to learn", "do not care"). Against this backdrop, he noted that creating a portfolio helped him realize that the course topics were useful despite his affinity to the material. He notes that this changed perspective made him more open to the knowledge of the course, suggesting an improvement is his motivation to learn.

"It made me a little more open to the knowledge from the class... because I didn't want to learn. I didn't care about the class, and it's really hard for you to learn something you don't care about, and you don't find interesting or -- but by doing it, I realize, well, you know, this -- I need to know this, whether I like it or not, I need it."

He admitted that the portfolio helped him to remember aspects of the class (the process plan) that were important. The portfolio creation experience also changed his conception of the portfolio.

"I mean if it wasn't for the portfolio, I would have completely forgotten about [the process plan].... I know that if [the professor] hadn't asked for [portfolio], I 
wouldn't have done it. But I also know that it is useful, they turn out pretty useful."

Portfolio made him think. Similar to Danielle, who identified that students do not have much chance to reflect and think, Ned also expressed a similar concern. Students can be so caught up in doing homework or being concerned about financial issues that they rarely have a chance to look back and seek the meaning of what they learned. Like Danielle, Ned asserted that creating a portfolio helped him learn the course material. Yet, unlike Danielle who thought she didn't need the portfolio to help her with this specific course, Ned thought the portfolio provided him a chance to think about how things connected and why the course is important.

"It does make you stop for a second and look at what you're doing and what career is and what you will be doing. So, you know, you always get caught up doing homework for the class, looking for scholarship. The portfolio gave me an option to stop for a second, stop doing homework, stop studying and crunching numbers and look at what I'm doing, so that was good. That was really like -- you question yourself when you're answering the survey, the pre and post portfolio survey. There are so many questions in engineering that you actually end up questioning yourself, so that's always good, I guess...

Yeah, definitely [helping him learn course knowledge]. Definitely. I hated the class, I did about the portfolio. I still didn't like it, but then I knew that it was an important class and still important to learn. So that was, I guess, the key difference that it made. That's the biggest influence that I hated the class, I didn't want to learn it, I didn't see how it was related to anything whatsoever, but when I did the portfolio, sat down and tried to convince other people of what I don't even believe myself, made me realize that the class is useful and that I do need to learn it."

Portfolio could be used as a way for presenting a profession. Unlike most of other students in the class, Ned had thought of doing research as his future career. Further, Ned thought that portfolios could be a useful tool in his future endeavors in this arena.

"Yeah, yeah. Definitely [have thought about any possible plan of using the portfolio in the future], um, I plan to go to grad school, um, so I think that if I'm doing research and I were to present my research in this -- using portfolio, it would give it more weight, it would be a better -- it's a little fancy. Um, I think it's a very organized, cleancut manner of showing things....Showing whatever it is you want to present. So if it's my research and I have all this data to present and I have all these pictures and all this information and everything that I need people to see and, Ph.D. committees or whatever, I think it -- it's a very structured way to show it. So I did -- I did think about it when I was doing it. ... I did think that I -that that's one useful tool that I should use in the future." 


\section{$\underline{\text { Paul }}$}

Paul is the student of the three profiled in this paper who reacted the most positively to the portfolio assignment in the survey. Specifically, Paul responded to the survey indicating a high level of agreement with statements about the benefits of the portfolio assignment. His high rating seems aligned with his high personal interest in mechanical engineering. While the other two students had taken the course only because it was a required course, Paul reported personal interest in the material ("I mean machining I think is interesting stuff"), which is also further evidenced by the fact that he is doing another project in the campus to gain extra mechanical engineering experience.

Despite these positive survey ratings, Paul, like Danielle and Ned, also held a negative impression of the portfolio assignment before creating the portfolio, as illustrated by the passages below.

Before creating the portfolio: "[The very first impression on the portfolio assignment is] Not probably all that favorable...I don't know, I mean I guess it just seemed kind of like one of these kind of meta assignments, like they're always asking you to do, like English classes and stuff about why you did this or explain your reasoning or something."

After finishing the portfolio: “_After I wrote it. I still wasn't feeling that good when I was writing it, so, you know -- but afterwards, yeah, I thought it was pretty useful. I mean I really did actually kind of think about what it meant to like understand the manufacturing process as far as like designing things and how that could change your design process or change things that you do, how you design things for ease of machinability or ease of manufacture and stuff like that."

After finishing the portfolio: "I think I thought when I was going into it that I would just kind of like BS most of it, and I think after I wrote it I didn't really do that much, it actually kind of -- yeah, that actually makes sense."

Paul also reported challenges similar to challenges reported by Danielle and Ned. For example, he also had thought a lot about his profession and had significant concern about the disconnect between the course topics and how they would be useful in that profession. His explanations of these challenges and his portfolio experience reveal that portfolio creation could provide support for students to make the connection between their course learning and their professional understanding.

Portfolio could be used as a way for presenting profession. Similar to Ned and Danielle, Paul also thought the portfolio to be a valuable tool for representation. In his case, Paul emphasized that using the portfolio had helped him to show what he learned and his experience.

"If they asked about what experience I have in that kind of area, or also, I mean [the portfolio] is useful in that it made me think about kind of what I learned, so if 
I got asked questions in an interview, I could explain to them what I know how to do or what I've learning in that kind of area."

Portfolio forces students to articulate connections between the course and profession. Similar to Ned, Paul also felt frustrated about learning in school, where students were too busy to do anything beyond completing the assignment. In his opinion, the whole purpose of taking classes becomes finishing the assignment and taking the exams, rather than learning knowledge and understanding the usefulness of the knowledge learned. In particular, students may not have the chance to think how the course fits into their profession. As a result of the portfolio creation, the student realized the significance of knowledge learned in the course and was forced to make the connection between the course and the profession.

"I think it's about making students think about -- I guess a lot of times you go through classes and you learn what you have to learn for the exams to do well on the exams, to do well on the homework, but maybe you don't think about like how it kind of fits into the bigger picture of what you want to do. I think it kind of forces you to really think about how this class and what you learned in the class really fits into like what should be, I guess, your whole goal of being a mechanical engineer professionally, and -- And, yeah, I mean I guess it just kind of forces you to think about how -- why what you're doing was important instead of just kind of floating through the class to get a grade out of it."

In his view, the specific mechanism through which the portfolio helped students to think about the course learning and their professional development was writing down their thoughts and laying out their evidence. This fits with Scardamalia's theory that writing can be a knowledge transformation process whereby a rhetorical problem (e.g., how do I explain this to you) could lead to deep thinking in the content space (e.g., what do I really know about this).

“Um, just having to put it into words. I mean you have to think about how you're gonna describe to someone else what the experience meant as far as what you got out of it. I mean it's not something I really think about after I'm done slogging through a homework assignment that took me five hours to do. I don't usually want to go back and reflect about, yeah, I guess that had a point. So it will force you to reflect on the whole -- the whole experience of the class."

Portfolio creates an opportunity for students to reflect and see the overall picture of the class. It seems that students often have difficulties clearly stating what they have learned in the class and why it was important. One reason could be that they do not have time, as mentioned by Danielle and Ned. Another reason could be that students are so overwhelmed by all the knowledge and details in the class that it is difficult to gain an overall picture of the course and make high level connections between the course and the discipline. 
“Because I think -- well, it's over like a long span of time, I guess, and I think also when you're actually in the class, like as far as having to get assignments done, having to go to class and meet, you don't really get much time to think about -- you know, it's kind of like this has to be done now, so I just got to get this done and turned in, and that's kind of what your goal is, I guess, when you're actually in the class, is just getting everything done, the work done, and so you don't really have much time to think about it. So when the portfolio assignment, I guess, came at the end, it was kind of like now is the time where we have to do all that thinking about what all those assignments and everything meant...

I think[the portfolio] helped learn like the -- kind of like overall picture of the class, which I think was the most important part of this class in particular...I mean I think -- 'cause the bulk of the class was learning about -- or trying to remember or memorize, you know, all the stuff that was just kind of like -- like just the small little details of each kind of manufacturing process, I guess, so I mean it didn't really -- I mean I remember him talking at the very beginning about like design processes and stuff, but for the vast majority of the class, it was kind of -- kind of the smaller, more specific stuff, and then, I guess, the portfolio assignment was kind of the thing that brought kind of the whole -- whole concept of the class, I guess, to the forefront."

\section{Portfolio helps students see the meaning of what they are learning and thus help them} retain the knowledge. Understanding the motivation for learning a particular topic is important because it can affect how much knowledge students will retain. Paul refers to this issue in the passage below. Danielle also expressed such a concern ("third of the course mostly wasted because you don't ever use it again").

"I mean [the portfolio] makes you, I guess -- I've had classes where I don't really see the point, like why I would need to know this, and it just makes me kind of like maybe not as willing to like retain the information maybe. Maybe I just want to like cram before the exam and forget everything afterwards, because why do I need to know, you know, and I think it's kind of important to know why you're taking the class and like why this ties into."

Portfolios provide students confidence in what they have learned. As Paul's passage below suggests, the portfolio can be a useful tool for helping students show both others and themselves what has been learned.

"I would say it kind of -- it just kind of put everything into definite terms, like this part -- you know, if someone had come up to me and made the argument that you -- well, if I was complaining that the class, well, you did get this out of it, you know, something like that, it was just kind of like -- it would be kind of like maybe a feeling, like I wouldn't dispute that, but it wasn't something like a real definite thing that I could like state and put my finger on maybe, and I think having to put it down in words helped me like -- like crystallize in my mind like having an actual almost feeling of what I learned or what I got out of the class." 


\section{Concluding Remarks}

Portfolios have the potential to function as a site for learning. We have been studying course-based professional portfolios in terms of how the construction of such portfolios can help students improve their professional knowledge and prepare for professional practice.

In the paper, we focused on how three students reacted to a required course-specific professional portfolio assignment. These students were chosen for analysis because they had reported very different reactions to the assignment in a post-assignment survey, yet all were able to speak to the experienced and/or potential benefits of the assignment. All three subjects felt that the portfolio could be a good way of presenting themselves to others and also that creating the portfolio could lead to increased confidence in their knowledge. Individually, students' comments on portfolios lean towards different directions. Danielle, who reported in the survey that the assignment did not really affect her learning in the course for which it was assigned, strongly emphasized the potential impacts of the portfolio on her learning particularly if the portfolio could be continuously included in multiple courses. Ned, whose survey responses suggested neutrality or ambivalence about whether the assignment had affected his learning in the course, reported in the interview (which occurred three weeks after the survey) that he had realized the portfolio had had a strong impact on him. In particular, he realized that the portfolio had helped him see the importance of the course and thus changed his "bias" towards the course. Paul, who had reported benefits on the survey, elaborated on these benefits in the interview. He noted that the portfolio had helped him see the importance of the course topics and provided him confidence in his knowledge by forcing him to think about the course and the connections between the course knowledge and professional discipline.

The various impacts we found in this study confirm and provide further empirical support for findings reported in the literature. For example, we found that portfolio creation could help students have a better understanding of what they learned as in Jalkio ${ }^{1}$, take full ownership for their portfolios as in Williams $2002^{2}$, help students enhance their learning as in Christy $1998^{3}$, see the major advantages in keeping a record of achievement as in Knott $2004^{4}$, feel positive about the value of portfolios for increased awareness of educational attainment as in Heinricher $2002^{5}$, assess their own competencies and take a more active role in the learning process as in Erikson $1998^{6}$, and even have a better understanding of course objectives as in Guan $2005^{7}$. Additionally, these results provide a basis for ensuring that a portfolio assignment helps the most students.

\section{Acknowledgements}

This work has been supported by the National Science Foundation through grant REC0238392, "Using portfolios to promote knowledge integration in engineering education." The authors wish to thank all of our research participants. The authors also wish to thank the members of the Laboratory for User-Centered Engineering Education for the insightful reviews and comments that helped to shape this paper. 


\section{Reference}

1. Jalkio, J.A. Using self-evaluation and student generated portfolios for assessment of student learning and course effectiveness. in Proceedings of the 2002 Annual ASEE Conference. 2002.

2. Williams, J.M., The engineering portfolio: Communication, reflection, and student learning outcomes assessment. International Journal of Engineering Education, 2002. 18(2): p. 199-207.

3. Christy, A.D. and L. Marybeth, Use of student portfolios in engineering instruction. Journal of Engineering Education, 1998. 87(2): p. 143-148.

4. Knott, E.W., W.K. Lohani, O.H. Griffin, G.V. Loganathan, G.T. Ade, and T.M. Wildman. Bridges for engineering education: Exploring ePortfolios in engineering education at Virginia Tech. in Proceedings of the 2004 Annual ASEE Conference. 2004.

5. Heinricher, A.C., J. E. Miller, L.E. Schacterle, N. Kildahl, and V. Bluemel, Undergraduate learning portfolios for institutional assessment. Journal of Engineering Education, 2002. 91(2): p. 249-253.

6. Erikson, C.A.J. and R.L. Ness. Portfolios: An effective assessment strategy for first year engineering students. in Proceedings of the 1998 Annual ASEE Conference. 1998.

7. Guan, Z., J. Yellin, J. Turns, and V. Kumar. User-centered design of course-based portfolios for mechanical engineering student learning. in ASME International Mechanical Engineering Congress and Exposition. 2005. Orlando, Florida. 